Frenkel, W.N., Born, B.J.H. van den, Munster, B.C. van, Korevaar, J.C., Levi, M., Rooij, S.E. de. The association between serum sodium levels at time of admission and mortality and morbidity in acutely admitted elderly patients: a prospective cohort study. Journal of the American Geriatrics Society: 2010, 58(11), 2227-2228

\begin{tabular}{|l|l|}
\hline $\begin{array}{l}\text { Postprint } \\
\text { Version }\end{array}$ & 1.0 \\
\hline $\begin{array}{l}\text { Journal website } \\
\text { Pubmed link }\end{array}$ & $\underline{\text { http://onlinelibrary.wiley.com/doi/10.1111/j.1532-5415.2010.03104.x/abstract }}$ \\
\hline DOI & $\underline{\text { http://www.ncbi.nlm.nih.gov/pubmed/21054304 }}$ \\
\hline
\end{tabular}

This is a NIVEL certified Post Print, more info at http://www.nivel.eu

\title{
The association between serum sodium levels at time of admission and mortality and morbidity in acutely admitted elderly patients: a prospective cohort study
}

\author{
WiJNANDA(NANNE) J. FRENKEL, MD BERT-JAN H. VAN DEN BORN, MD, PHD

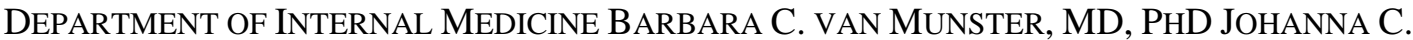 \\ KOREVAAR, PHD DEPARTMENT OF CLINICAL EPIDEMIOLOGY, BIOSTATISTICS AND \\ BioINFORMATICS MARCEL LEVI, MD, PHD SOPHIA E. DE ROOIJ, MD, PHD DEPARTMENT OF \\ Internal MEdicine ACADEMiC MEdicAl CENTRE AMSTERDAM, THE NETHERLANDS
}

To the Editor: Throughout life, serum sodium level is maintained within narrow limits despite continuous variations in water and salt intake. Renal sodium transporters and osmoreceptors in the hypothalamus that control secretion of antidiuretic hormone (ADH) and regulate thirst are the main governors of sodium and water homeostasis. Disturbances in water and sodium homeostasis are frequently observed in elderly patients and, when severe, may lead to loss of consciousness, coma, or even death. ${ }^{1}$ Deviations in serum sodium have been associated with mortality and functional decline, but the association with functional decline has, to the knowledge of the authors, never been prospectively examined. The present study assessed the association between deviations in serum sodium levels at time of admission and 3-month mortality and functional decline in acutely admitted elderly patients.

\section{METHODS}

Nine hundred forty-five eligible patients aged 65 and older who were acutely admitted to the Department of Internal Medicine of the Academic Medical Centre, Amsterdam, the Netherlands between November 2002 and July 2007 were enrolled. The primary endpoints of the study were mortality in the hospital and by 3 months after admission. Secondary endpoint was decline in functional status, defined as a loss in one or more activity of daily living (ADL) functions of the Katz ADL index.2 Telephone interviews with patients or their relatives were conducted 3 months after hospital admission. Laboratory analyses were performed within 24 hours of admission. Based on the reference values used in our hospital, 307 patients (34.3\%) had hyponatremia (sodium $0135 \mathrm{mmol} / \mathrm{L}$ ) and $22(2.5 \%)$ had hypernatremia (sodium $4145 \mathrm{mmol} / \mathrm{L}$ ). Because of the leftward shift, the distribution of serum sodium in the population of interest was used to stratify participants according to _ 1 standard deviation around the mean serum sodium level. Comorbidity was defined as possible confounders selected using univariate analysis for mortality, such as history of 
Frenkel, W.N., Born, B.J.H. van den, Munster, B.C. van, Korevaar, J.C., Levi, M., Rooij, S.E. de. The association between serum sodium levels at time of admission and mortality and morbidity in acutely admitted elderly patients: a prospective cohort study. Journal of the American Geriatrics Society: 2010, 58(11), 2227-2228

malignancy, renal failure, heart failure, or liver failure. Logistic regression analysis was performed to determine the risk for 3-month mortality and functional decline.

\section{[FIGURE 1]}

\section{RESULTS}

Eight hundred ninety-five eligible patients with a mean age of $78 \pm 8.7$ were enrolled in the study; $53.4 \%$ were female. Fifty patients (5.3\%) were excluded because of unknown serum sodium levels $(\mathrm{n}=31)$ or drug-induced hypo- or hypernatremia $(\mathrm{n}=19)$. The mean serum sodium level of the cohort was $136 \pm 5.6 \mathrm{mmol} / \mathrm{L}$. Three-month mortality was higher in the low-sodium group (107-130 mmol/L) than the reference group (130- $142 \mathrm{mmol} / \mathrm{L}$ ) (odds ratio $(\mathrm{OR})=1.5,95 \%$ confidence interval $(\mathrm{CI})=1.0-2.2, \mathrm{P}=.05$; Figure 1$)$. After adjustment for comorbidity, 3-month mortality in the low-sodium group was comparable with that of the reference group $(\mathrm{OR}=1.2,95 \% \mathrm{CI}=0.8-1.9, \mathrm{P}=0.6)$. Katz ADL index before admission was higher in the low- $(6.7 \pm 4.5)$ and high- $(7.4 \pm 5.3)$ sodium groups than the reference group (4.7 \pm 4.2 , Po.01). In all groups, the Katz ADL index increased equally after 3 months in all sodium groups but remained different for the low- and high-sodium groups and the reference group.

\section{DISCUSSION}

This study showed that hyponatremia is frequently observed in acutely admitted elderly patients. A higher prevalence of hypo- and hypernatremia was found than in other reports that examined disturbances in serum sodium levels in acutely hospitalized patients.3,4 Agerelated physiological changes may increase susceptibility to disturbances in water and salt balance.5,6 The fact that the average age of participating patients was higher than in previous studies may therefore explain the high prevalence of hyponatremia in the current study.7,8 Low serum sodium levels at presentation were associated with a 50\% greater risk of mortality, although the association between serum sodium levels and mortality disappeared after adjusting for comorbidity, suggesting that the effect of deviations in serum sodium levels on mortality is associated more with a person's underlying disease state than deviations in serum sodium level per se. Similar results were found after we performed posthoc analysis in three groups according to reference value used in our hospital (normal sodium 135-145 mmol/L). Finally, an increase in the Katz ADL index before admission was observed in the low- and high-sodium groups, suggesting lower functional status in patients who presented with a deviation in serum sodium. At 3 months, the change in the Katz ADL index was still different across sodium groups, but the change in functional status was equal in all groups, suggesting that poorer functional status is associated with greater risk of hypoand hypernatremia, but there was no evidence of functional decline in association with deviations in serum sodium. In conclusion, hyponatremia is common in acutely admitted elderly patients and is associated with greater risk of mortality and longer length of hospital stay, although it was not possible to demonstrate that disturbed serum sodium levels had an independent effect on mortality risk or functional status.

\section{ACKNOWLEDGMENTS}

Conflict of Interest: The editor in chief has reviewed the conflict of interest checklist provided by the authors and has determined that the authors have no financial or any other kind of personal conflicts with this paper. Author Contributions: WJF: conception and design, acquisition of subjects and data, analysis and interpretation of data, preparation of the manuscript. BJvdB: conception and design, interpretation of data, preparation of the manuscript, critical revision of the manuscript for important intellectual content. SEdR: conception and design, interpretation of data, critical revision of the manuscript for 
Frenkel, W.N., Born, B.J.H. van den, Munster, B.C. van, Korevaar, J.C., Levi, M., Rooij, S.E. de. The association between serum sodium levels at time of admission and mortality and morbidity in acutely admitted elderly patients: a prospective cohort study. Journal of the American $<7$ Geriatrics Society: 2010, 58(11), 2227-2228

important intellectual content. BvM: acquisition of subjects and data, analysis and nivel interpretation of data, critical revision of the manuscript. JCK: analysis and interpretation of data, critical revision of the manuscript for important intellectual content ML: conception and design, critical revision of the manuscript for important intellectual content. Sponsor's Role: No sponsor involved in the study.

\section{REFERENCES}

1. Hawkins RC. Age and gender as risk factors for hyponatremia and hypernatremia. Clin Chim Acta 2003;337:169-172.

2. Katz S, Akpom CA. A measure of primary sociobiological functions. Int J Health Serv 1976;6:493-508.

3. Waikar SS, Mount DB, Curhan GC. Mortality after hospitalization with mild, moderate, and severe hyponatremia. Am J Med 2009;122:857-865.

4. Zilberberg MD, Exuzides A, Spalding J et al. Epidemiology, clinical and economic outcomes of admission hyponatremia among hospitalized patients. Curr Med Res Opin 2008;24:1601-1608.

5. Allison SP, Lobo DN. Fluid and electrolytes in the elderly. Curr Opin Clin Nutr Metab Care 2004;7:27-33.

6. Tietz NW, Shuey DF, Wekstein DR. Laboratory values in fit aging individualssexagenarians through centenarians. Clin Chem 1992;38:1167-1185.

7. Asadollahi K, Beeching N, Gill G. Hyponatraemia as a risk factor for hospital mortality. QJM 2006;99:877-880.

8. Kennedy PG, Mitchell DM, Hoffbrand BI. Severe hyponatraemia in hospital inpatients. BMJ 1978;2:1251-1253.

\section{RELIABILITY AND VALIDITY OF THE VISUAL ANALOGUE SCALE FOR FEAR OF FALLING IN OLDER PERSONS}

To the Editor: Fear of falling (FOF) is a serious problem in older adults living in the community. ${ }^{1-4}$ The main risk factor for developing FOF is experiencing at least one fall. ${ }^{1,4}$ FOF is associated with recurrent falling, less physical activity, less confidence in performing activities of daily living, restriction of activities, and overall lower quality of life (QoL) ${ }^{1-4}$ Different definitions for FOF have resulted in the development of many different instruments to measure FOF. ${ }^{5}$ A new and brief method to measure FOF is a visual analogue scale (VAS). A VAS is useful for measuring a variety of subjective phenomena and provides a convenient, easy, and rapidly administered measurement strategy. ${ }^{6}$ The VAS for FOF (VAS-FOF) uses a numeric scale (1-10) to measure perceived FOF after a fall, with 1 representing no FOF and 10 representing extreme FOF. Twenty-three fall prevention clinics in the Netherlands currently use the VAS-FOF in clinical practice. This study aimed to assess the reliability and validity of the VAS-FOF as a method of assessing FOF in older persons who have experienced a fall. 
Frenkel, W.N., Born, B.J.H. van den, Munster, B.C. van, Korevaar, J.C., Levi, M., Rooij, S.E. de. The association between serum sodium levels at time of admission and mortality and morbidity) in acutely admitted elderly patients: a prospective cohort study. Journal of the American $<7$ Geriatrics Society: 2010, 58(11), 2227-2228

\section{FIGURES}

Figure 1
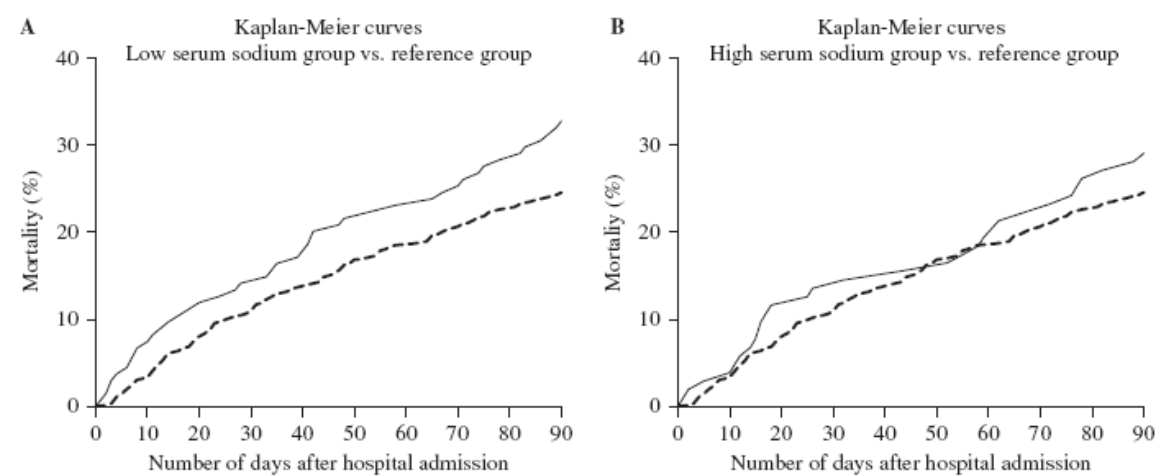

Figure 1. Mortality 90 days after admission in acutely admitted elderly patients: Kaplan-Meier curves. (A) Straight line, low-serum sodium group (107-130 mmol/L); dotted line, reference group (130-142 mmol/L) $(32.8 \%$ vs $24.6 \%$; $P=.05)$ (B) Straight line, highserum sodium group $(142-162 \mathrm{mmol} / \mathrm{L})$; dotted line, reference group $(130-142 \mathrm{mmol} / \mathrm{L})(26.2 \% \mathrm{vs} .24 .6 \% ; P=.30)$. 